\title{
UWB Antenna with 3.5-/5.5-GHz Dual Band- Notched Characteristics Using Two Radiating Stubs
}

\author{
M. Akbari, R. Movahedinia, A. R. Sebak, \\ Electrical and Computer Department, Concordia \\ University, Montreal, Quebec H3G 1M8, Canada \\ akbari.telecom@gmail.com, mo_akba@encs.concordia.ca \\ N. Rojhani \\ Young Researchers and Elite club, South Tehran Branch, \\ Islamic Azad University, Tehran, Iran
}

\author{
Saman Zarbakhsh \\ Young Researchers and Elite club, Central Tehran \\ Branch, Islamic Azad University, Tehran, Iran \\ Vijay Devabhaktuni, Senior Member, IEEE \\ Electrical and Computer Department, the University of \\ Toledo Toledo, OH 43606 \\ Vijay.Devabhaktuni@utoledo.edu
}

\begin{abstract}
UWB applications is suggested. The antenna is able to filter both of the interference frequency bands of WiMAX and WLAN. The antenna consists of two radiating stubs, a partial ground, and a feed-line. In the configuration, by etching an inverted T-shaped slot on the ground plane, extra resonance is excited, thus broad impedance bandwidth can be obtained. The measured results exhibits that the antenna can cover the bandwidth from 2.7 to 13.0 GHz for VSWR $\leq 2$ excluding the rejected bands from 3.0 to 3.7 $\mathrm{GHz}$ and from 4.9 to $6.0 \mathrm{GHz}$.
\end{abstract}

\section{INTRODUCTION}

Since the FCC dedicated the frequency band of $3.1 \mathrm{GHz}$ to $10.6 \mathrm{GHz}$ for commercial use in 2002, Ultra-wideband (UWB) technologies have attracted considerable attention [1]. In wireless communication systems in particular UWB, one of main subjects is the design of an antenna in a compact size while providing broadband characteristic over all of the operating band. Consequently, a huge number of planar microstrip antennas with various configurations have been experimentally characterized [2 - 4]. Although, there are the set of interferences frequency bands over the released UWB operation bandwidth which the most important among them are the Wireless Local Area Network (WLAN) and Worldwide Interoperability for Microwave Access (WiMAX), which operate with the center frequencies of $5.2 \mathrm{GHz}(5150-5350 \mathrm{MHz}), 5.8 \mathrm{GHz}(5725-5825$ $\mathrm{MHz})$ for WLAN and $3.5 \mathrm{GHz}(3400-3690 \mathrm{MHz}), 5.5 \mathrm{GHz}$ (5250-5850 MHz) bands for WiMAX. Thus, the potential electromagnetic interference (EMI) problems are serious and need more attention. Recently, the big number of band-notched UWB antennas have been studied and reported, which are able to filter the certain band within the ultra-wide passband without mounting additional bandstop filters [5-10]. In this letter, a new microstrip antenna with band-notched functions for UWB applications is suggested. By using a series of new techniques and designs on both radiating patch and ground plane, wide band and band-notched UWB characteristics can be obtained. The practical prototype was fabricated and measured, and the results exhibit an acceptable agreement with the simulated ones. Details of the antenna design and parameter study are presented and discussed as follows.

\section{ANTENNA DESIGN}

The configuration of the antenna is illustrated in Figure 1. The antenna is fabricated on a $18 \times 12 \mathrm{~mm} 2$ FR4 substrate with thickness $1 \mathrm{~mm}$ and relative permittivity $\mathrm{gr}=4.4$. The antenna consists of two radiating stubs, a partial ground, and a feed-line. As exhibited in Figure 1, to obtain desirable impedance bandwidth, a T-shaped slot is etched from partial ground plane symmetrically and in order to obtain both of the notched bands at centre frequency of 3.5 and $5.5 \mathrm{GHz}$ respectively, the structure of radiating patch is varied to two radiating stubs and a long feed-line. The radiating stubs is connected to a $50 \Omega$ microstrip line with width $2 \mathrm{~mm}$. The whole antenna is optimized by the electromagnetic simulation software of Ansoft High Frequency Simulation Structure (HFSS) based on the finite element method (FEM) [11], and values of some optimized parameters are depicted in Figure 1. The following portion is related to the antenna design process and the effect of various parameters on VSWR. 

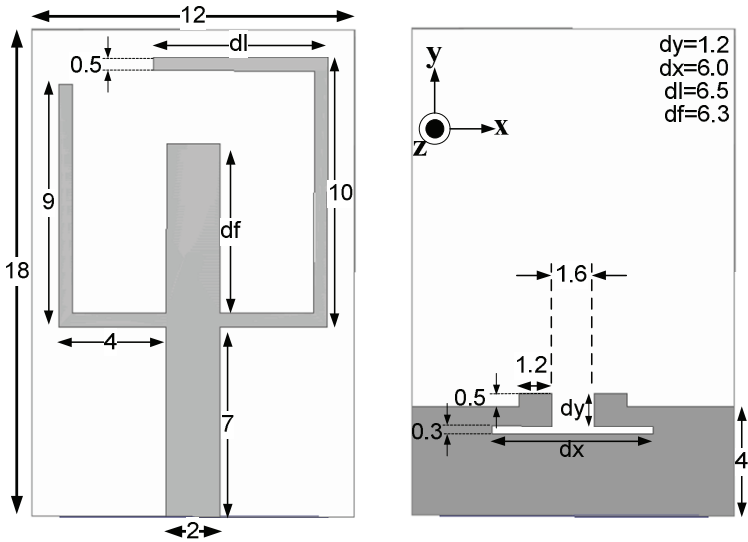

Fig. 1. Geometry of the proposed antenna

\section{ANTENNA PERFORMANCE AND DISCUSSION}

In this section, the proposed antenna with different design parameters were fabricated, and the numerical and experimental results of the input impedance and radiation characteristics are presented. The parameters of the antenna are investigated by changing one parameter at a time and fixing the others. As illustrated in Figure 2, the simulated reflection coefficient characteristics for three antennas with different ground structures are presented. With regard to it, Ant.1 (primary monopole square antenna) has an impedance bandwidth from 3.6 to $6.3 \mathrm{GHz}$, while Ant.2 with an inverted T-shaped slot on the ground plane increases the bandwidth from 3.5 to 10.8. By changing the ground plane as shown in Ant. 3, a considerable resonance is created at $12.5 \mathrm{GHz}$ which improves impedance bandwidth from 3.5 to $13.5 \mathrm{GHz}$. As far as Figure 3 is concerned, simulated reflection coefficient characteristics of the antenna are shown for various values $d x$ where $d y$ is constant $(\mathrm{dy}=1.2 \mathrm{~mm})$. From Figure 3 can be concluded that the upper frequency of the impedance bandwidth is affected by using an inverted T-shaped slot on the ground plane, and also by optimizing it, additional third resonant frequency is more excited. Besides, the upper-edge frequency of the impedance bandwidth is decreased from 11.9 to $13.5 \mathrm{GHz}$ by increasing value $\mathrm{dx}$ from 5.0 to $6.0 \mathrm{~mm}$. Therefore, the optimized $\mathrm{dx}$ is 6.0 $\mathrm{mm}$. On the other hand, the effect of varying parameter dy on reflection coefficient characteristics where $\mathrm{dx}$ is constant $(d x=6.0 \mathrm{~mm})$ has been investigated in Figure 4 . It can be found out that the effect of dy at shifting the upper-edge frequency of the impedance bandwidth is more than dx. Regarding to Figure 4 , the best value for dy is $1.2 \mathrm{~mm}$. As mentioned before, to achieve an UWB antenna with notched band function, two new techniques are employed containing two radiating stubs and a feed-line extended. By adjusting these three parameters, two notched bands at center frequencies $3.5 \mathrm{GHz}$ and $5.5 \mathrm{GHz}$ can be earned, respectively. As shown in Figure 5, the VSWR characteristics for four various antenna structures reflecting design procedure are compared with each other. As it is obvious in Figure 5, Ant. I was optimized and it ended up a broad impedance bandwidth.

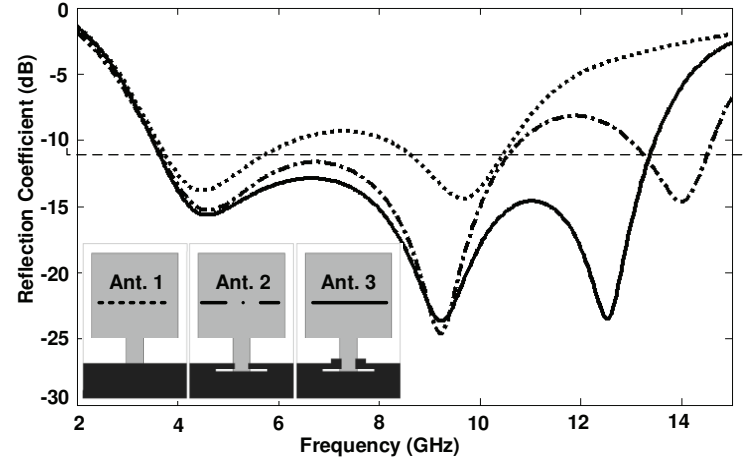

Fig. 2. The comparison of simulated reflection coefficient characteristics of

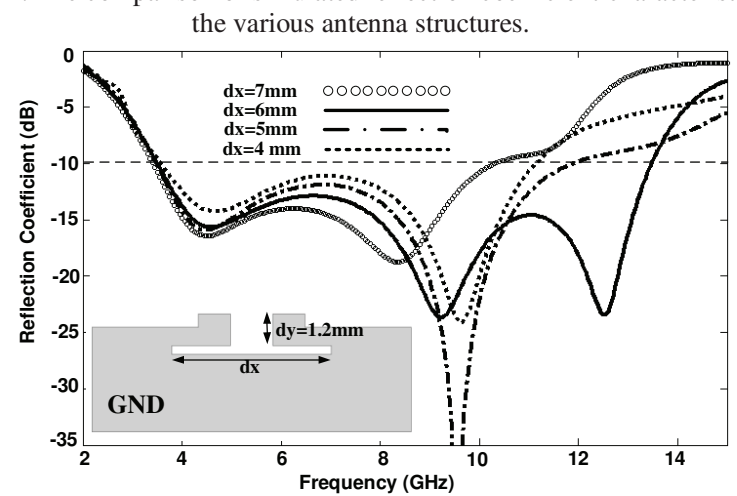

Fig. 3. Simulated reflection coefficient characteristics of the antenna with an inverted T-shaped slot on the ground for different values of $\mathrm{dx}$ where dy is constant $(\mathrm{dy}=1.2 \mathrm{~mm})$.

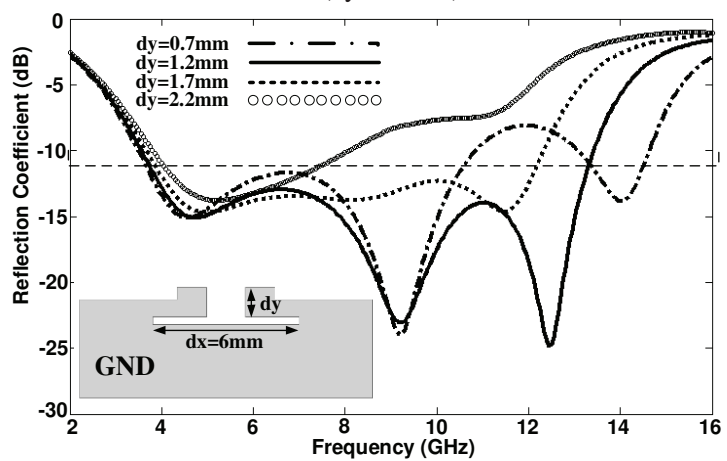

Fig. 4. Simulated reflection coefficient characteristics of the antenna with an inverted $\mathrm{T}$-shaped slot on the ground for different values dy where $\mathrm{dx}$ is constant $(\mathrm{dx}=6.0 \mathrm{~mm})$.

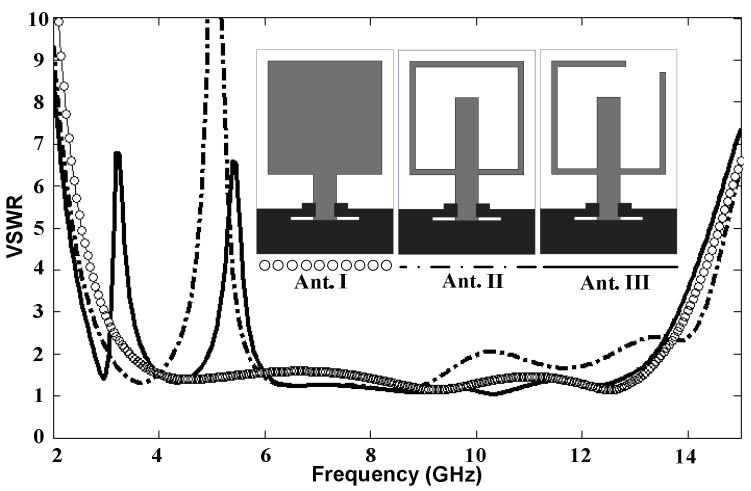

Fig. 5. The comparison of Simulated VSWR characteristics of the various antenna structures. 
With comparison Ant. II and III, by varying ring radiating patch to two radiating stubs firstly the bandwidth is improved and secondly both notched bands at center frequencies of $3.5 \mathrm{GHz}$ and $5.5 \mathrm{GHz}$ are produced. Figure 6 shows that Simulated VSWR characteristics of the antenna for different values dl. As it is apparent, dl has a direct effect on the control of central frequency of the lower notched band. In other words, the center frequency is decreased from $3.8 \mathrm{GHz}$ to $3 \mathrm{GHz}$ with increasing $\mathrm{dl}$ from $4.5 \mathrm{~mm}$ to $7.5 \mathrm{~mm}$. Since by shifting the lower notched band, the upper notched band is nearly station, therefore two notched bands are controllable and independent. With regard to desirable notched band (3.3-3.69), the best value of $\mathrm{dl}$ is $6.5 \mathrm{~mm}$. As mentioned before, to obtain notched band at center frequency $5.5 \mathrm{GHz}$, the feed-line extended is used. Figure 7 exhibits the simulated band-rejected feature by varying df.

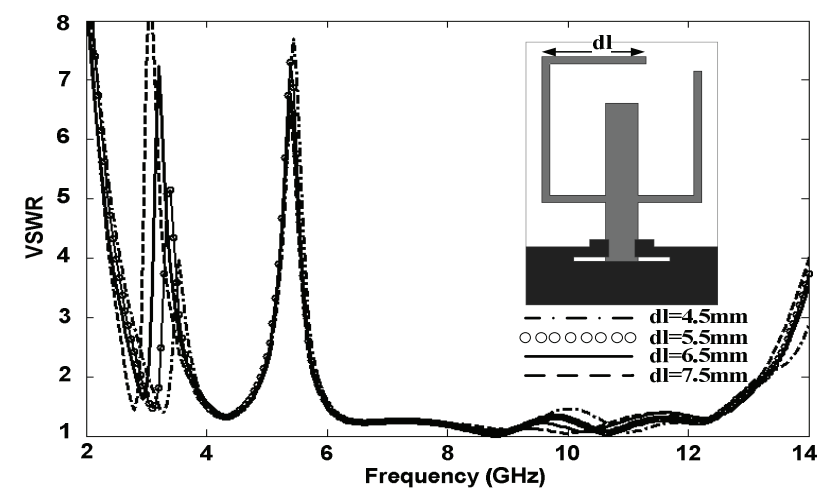

Fig. 6. Simulated VSWR characteristics of the antenna for different values dl.

As illustrated in Figure 7, tuning the length of the feed-line can earn a controllable center-rejected frequency range from 5 to $5.9 \mathrm{GHz}$ for the second notched band. Figure 7 also depicts that $\mathrm{df}$ is a main factor to control the rejected VSWR value.

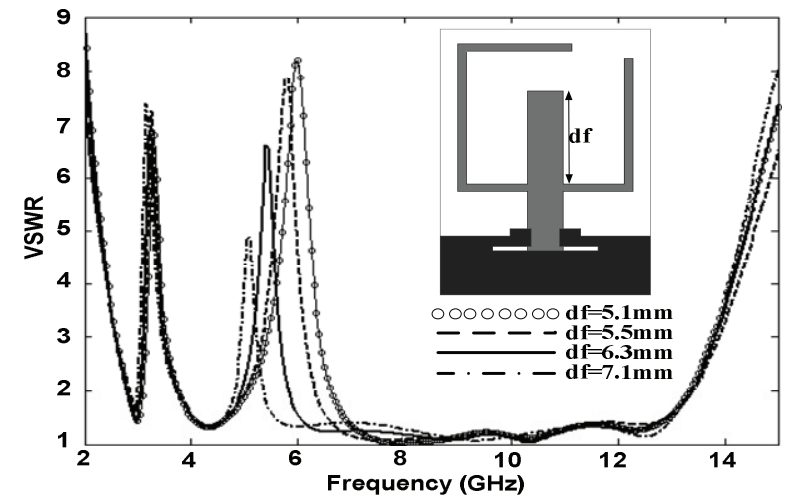

Fig. 7. Simulated VSWR characteristics of the antenna for different values df

As length df increases from 5.1 to $7.1 \mathrm{~mm}$, the central frequency of the notched band is reduced from 6 to $5 \mathrm{GHz}$. The acceptable value of $\mathrm{df}$ is $6.3 \mathrm{~mm}$. To understand the phenomenon behind this dual stop-band characteristic, the simulated current distributions on two radiating stubs and feedline extended at both $3.5 \mathrm{GHz}$ and $5.5 \mathrm{GHz}$ are depicted in Figure 8 . It can be found out from Figure 8 that at frequency $3.5 \mathrm{GHz}$ the greatest current is concentrated at around of two radiating stubs. While at $5.5 \mathrm{GHz}$ it is focused at around not only two radiating stubs but also the feed-line. All of them consequently end up the acceptable VSWR within both notched bands. The proposed antenna has been fabricated based on the dimensions presented in Figure 1. It also was tested in the Antenna Measurement Laboratory at Iran Telecommunication Research Center. The VSWR of the proposed antenna has been measured using an Agilent E8362B network analyzer in its full operational span $(10 \mathrm{MHz}-20 \mathrm{GHz})$. The simulated and measured VSWR of the fabricated antenna are also shown in Figure 8 . The fabricated antenna are able to cover impedance bandwidth from 2.7 to $13 \mathrm{GHz}$ for $\mathrm{VSWR} \leq 2$ with two notch bands around 3.0 to $3.7 \mathrm{GHz}$ and from 4.9 to $6.0 \mathrm{GHz}$.

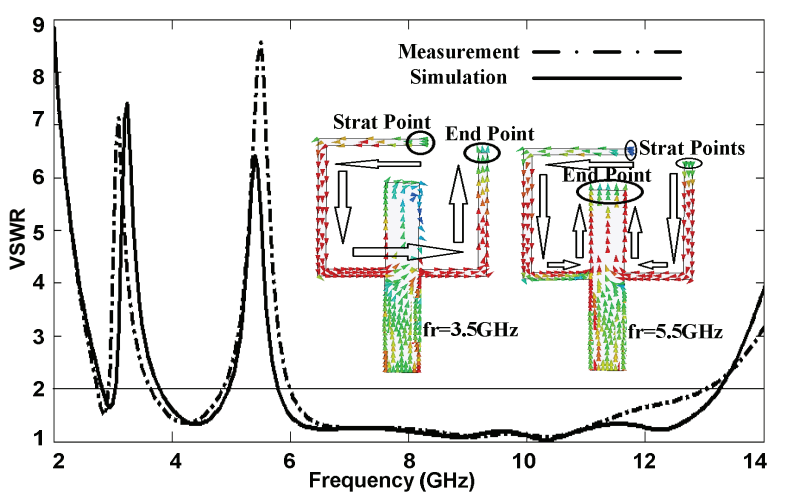

Fig. 8. Measured and simulated VSWR for the antenna and current distribution at frequencies $3.5 \mathrm{GHz}$ and $5.5 \mathrm{GHz}$.

The photo of implemented antenna is obvious in Figure 9. To confirm the accurate reflection coefficient characteristics for the designed antenna, it is recommended that the manufacturing and measurement process need to be performed carefully. Figure 10 exhibits the radiation patterns of the antenna with notched bands at frequencies 4.7 and $8.5 \mathrm{GHz}$ in E-plane (yzplane) and H-plane (xz-plane). It is distinctly revealed from the Figure that H-plane patterns are purely omnidirectional at all frequencies, while the E-plane patterns similarly show the expected monopole-like behaviors. Figure 11 depicts the maximum gain of the antenna with and without notched band. A sharp decrease of maximum gain in the notched bands at both $3.5 \mathrm{GHz}$ and $5.5 \mathrm{GHz}$ are illustrated. For other frequencies outside the notched frequency band, the antenna gain with the slot is similar to those without it.

\section{CONCLUSION}

A new ultra wideband monopole antenna with dual notched band characteristic has been suggested. The desired band-stop function is obtained by two radiating stubs and the extended feed-line. Measured results show the dual rejected bands can be tuned flexibly and independently. The measured results exhibited that the antenna can cover the bandwidth from 2.7 to 13.0 GHz for VSWR $\leq 2$ excluding the notched bands from 3.0 to $3.7 \mathrm{GHz}$ and 4.9 to $6.0 \mathrm{GHz}$. Desirable VSWR and radiation pattern characteristics are obtained on the frequency band of interest. 


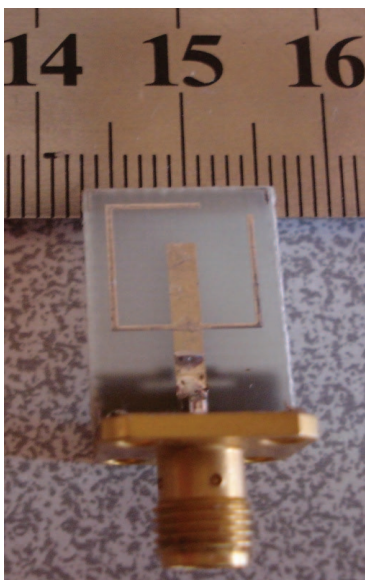

Fig. 9. Photograph of the fabricated antenna.

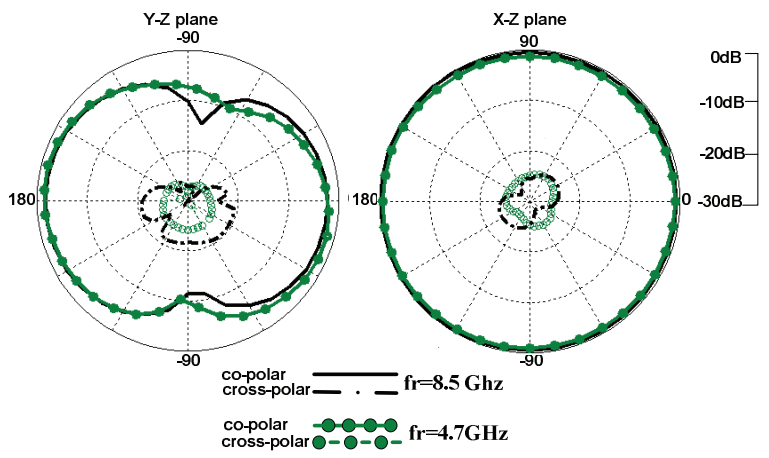

Fig. 10. Radiation patterns of the proposed antenna at 4.7 and $8.5 \mathrm{GHz}$

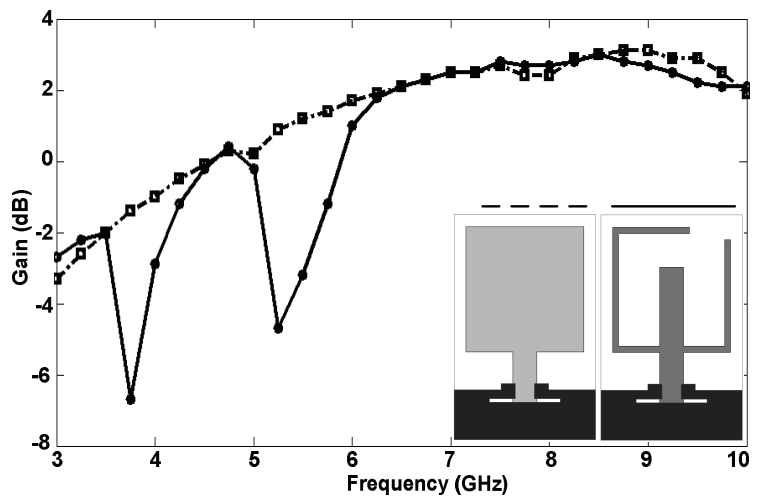

Fig. 11. Gain comparisons for the ordinary square antenna (without notched band), and the proposed antenna (with notched band)

\section{REFERENCES}

1. Federal Communications Commission, First Report and Order on Ultra-Wideband Technology, FCC 02 - 48, Washington, DC, April 22, 2002.

2. M. Akbari, M. Koohestani, Ch. Ghobadi, J. Nourinia, A New Compact Planar UWB Monopole Antenna, International Journal of RF and Microwave Computer-Aided Engineering, Vol. 21, No. 2 (2011), 216-220.

3. M. Akbari, M. Koohestani, Ch. Ghobadi, J. Nourinia, Compact CPW-Fed Printed Monopole Antenna with Super wideband Performance, Microwave Opt Technol Lett, Vol. 53, No. 7 (2011), 1481-1483.

4. M. Mighani, M. Akbari, N. Felegari, Design of a Small Rhombic Monopole Antenna With parasitic rectangle into slot of the feed line for SWB Application, The Applied Computational Electromagnetic Society, Vol. 27, No. 1 ( 2012), 74-79.

5. M. Akbari, S. Zarbakhsh, M. Marbouti, A New Slot Antenna With Triple Stop-Band Performance For UWB Applications, Microwave Opt Technol Lett, Vol. 55, No. 10 (2013), 2350-2354.

6. M. Mighani, M. Akbari, N. Felegari, "A CPW Dual Band Notched UWB Antenna", Applied Computational Electromagnetics Society (ACES) Journal, vol. 27, no. 4, pp. 352359, April 2012.

7. M. M. Abdollahi, H. R. Dalili Oskouei, M. Akbari, M. Mighani, A novel compact UWB antenna with triple band-notches for WiMAX/ WLAN/ ITU bands, The Applied Computational Electromagnetic Society, VOL. 27, NO. 12 (2012), 1014-1021.

8. Lin, C. C., P. Jin, and W. Ziolkowski, "Single, dual and tri- bandnotched ultrawideband (UWB) antennas using Capacitively loaded loop (CLL) resonators", IEEE Trans. on Antennas and Propag., Vol. 60, 102-109, 2012.

9. Peng, L. and C. L. Ruan, "UWB band-notched monopole antenna design using electromagnetic-bandgap structures", IEEE Trans. on Microwave Theory and Tech., Vol. 59, 1074-1081, 2011.

10. Kelly, J. R., P. S. Hall, and P. Gardner, "Band-notched UWB antenna incorporating a microstrip open-loop resonator", IEEE Trans. on Antennas and Propag., Vol. 59, 3045-3048, 2011.

11. Ansoft High Frequency Structure Simulation (HFSSTM), Ver. 13, Ansoft Corporation, 2010. 